\title{
Respiratory-Related Hospitalizations following Prophylaxis in the Canadian Registry for Palivizumab (2005-2012) Compared to Other International Registries
}

\author{
Bosco Paes, ${ }^{1,2}$ Ian Mitchell, ${ }^{3}$ Abby Li, ${ }^{4}$ Tetsuhiro Harimoto, ${ }^{4}$ and Krista L. Lanctôt ${ }^{4}$ \\ ${ }^{1}$ Department of Pediatrics, McMaster University, Hamilton, ON, Canada L8S 4 K1 \\ ${ }^{2}$ McMaster Children's Hospital, 1280 Main Street West, Room HSC-3A, Hamilton, ON, Canada L8S 4K1 \\ ${ }^{3}$ Department of Pediatrics, University of Calgary, Calgary, AB, Canada T3B $6 A 8$ \\ ${ }^{4}$ Medical Outcomes and Research in Economics (MORE) Research Group, Sunnybrook Health Sciences Centre, University of Toronto, \\ Toronto, ON, Canada M4N 3M5
}

Correspondence should be addressed to Bosco Paes; paes@mcmaster.ca

Received 25 February 2013; Accepted 17 April 2013

Academic Editor: Roberto Burioni

Copyright (C) 2013 Bosco Paes et al. This is an open access article distributed under the Creative Commons Attribution License, which permits unrestricted use, distribution, and reproduction in any medium, provided the original work is properly cited.

\begin{abstract}
Respiratory syncytial virus (RSV) infection occurs commonly in infants aged $\leq 2$ years, and severe infection results in hospitalization with accompanying morbidity and mortality. Palivizumab has been available for prophylaxis for the past 15 years. Prospective data on patients who received palivizumab from 2005 to 2012 has been assembled in the Canadian registry (CARESS) to document utilization, compliance, and health outcomes in both hospital and community settings. Long-term data is necessary to evaluate the impact of palivizumab on the incidence of RSV infections, minimize healthcare resources, and identify which infant subpopulations are receiving prophylaxis. A database search was also conducted for similar information from published registries, and hospitalization rates were compared to results from randomized clinical trials (RCTs).Overall hospitalization rates (percent; range) for respiratory-related illnesses and RSV-specific infection in infants who meet standard indications for prophylaxis were 6.6 (3.3-7.7) and 1.55 (0.3-2.06), respectively, in CARESS, which closely aligns with registry data from 4 other countries, despite the former comprising the largest cohort of complex patients internationally. Overall RSV-related hospitalization rates were lower across registries compared to equivalent patients in RCTs. Registry data provides valuable information regarding real-world experience with palivizumab, while facilitating the genesis of new research themes.
\end{abstract}

\section{Introduction}

Respiratory syncytial virus (RSV) continues to play a dominant role among the spectrum of viruses causing acute lower respiratory infection and subsequent hospitalization in infants and young children [1-6]. The burden of illness with accompanying morbidity, mortality, and associated healthcare costs is equally significant both within the community and world-wide [7-13].

Palivizumab, a humanized monoclonal antibody that targets the A antigenic site of the F-protein of RSV for the prevention of disease in high-risk children, demonstrates both neutralizing and fusion-inhibitory activity [14]. It was licensed in the USA by the Food and Drug Administration
(FDA) in 1998 and subsequently by the European Medicines Evaluation Agency (EMEA) in 1999. Since its release, two major randomized, double-blind, placebo controlled trials $[15,16]$ and several follow-up studies $[17,18]$ have established the safety and efficacy of palivizumab in premature infants aged $<6$ months who are $\leq 35$ weeks gestational age and in children $<2$ years with hemodynamically significant congenital heart (HSCHD) or chronic lung disease (CLD).

Over several years, international registries have closely monitored patients who have received RSV prophylaxis, in order to determine utilization and compliance relative to country-specific or national pediatric guidelines and position statements [19-22]. The Canadian Registry for the evaluation of palivizumab (CARESS) was initiated in 2005, with 
the principal objective of documenting usage, compliance, and health outcomes of infants receiving RSV prophylaxis in both hospital and community settings during the annual RSV seasons. The registry tracks data on patient demographics, annual indications for prophylaxis, incidence of RSV infections, rates of hospitalization for respiratory-related and RSV-related illnesses with respective lengths of hospital stay, risk factors that govern time to hospitalization, acquired morbidities following hospital admission, and safety and compliance with palivizumab.

The primary objective of this report is to document hospitalizations for respiratory illnesses (RIH) and RSV-specific infection (RSVH) within CARESS that spans the 2005-2012 RSV seasons and compare our results with published data from similar international registries and published randomized clinical trials (RCTs).

\section{Material and Methods}

Infants who received at least one dose of palivizumab during any RSV season from 2005 to 2012 were eligible for inclusion in CARESS, if they had at least one of the following riskfactors: prematurity ( $\leq 35$ completed weeks gestational age [GA]) without underlying medical disorders, CLD, HSCHD, or other "off-label" provincially approved medical conditions such as Down syndrome, congenital airway anomalies, immunodeficiency, or neuromuscular disorders. Preterm infants, 33-35 completed weeks GA, qualify for palivizumab only if they are considered at moderate (score 49-64) to high (score 65-100) risk for severe RSV infection and hospitalization based on a validated, Canadian risk-scoring model [23]. Children were excluded if a parent or legal guardian could not communicate in either English or French. Additionally, infants had to be recruited after their first injection of palivizumab and preferentially before receiving their third injection.

Subjects were enrolled by the local physician investigator and/or research nurse, which included providing the parent or legal guardian with an information package and consent form for review. Once consent was obtained, the research nurse completed an enrolment form to collect baseline data on patient demographics, prior medical history, neonatal course, and details of palivizumab administration. Following study initiation, the research nurse at the local site contacted the parent or legal guardian either in person or by telephone monthly, until the end of the RSV season, obtaining data on palivizumab administration, changes in baseline information, and specific facts regarding possible respiratory infections since the last contact. In the event of a hospitalization, and with parental consent, the relevant hospital records were reviewed by the site's research nurse for detailed information on patient diagnosis, reason for hospitalization, length of stay, days on respiratory support and/or intubation, and RSV specimen type and diagnostic test, as reported in the discharge summary. Collected data was logged into a central website.

Compliance was evaluated by two methods: actual number of doses prescribed versus expected number of doses for the duration of the RSV season and interdose interval.
Palivizumab clinics currently administer about 5 monthly injections of palivizumab at $30 \pm 5$ day intervals, based on pharmacokinetic evidence from RCTs [15, 16, 24-26]. For expected number of doses, the number was calculated assuming monthly injections from the first dose to the end of the RSV season. The criterion for the start and end of the RSV season was defined by the previous study conducted by the Pediatric Investigators Collaborative Network on Infections in Canada [27]. For number of days between injections, $30 \pm 5$ day intervals were considered acceptable (i.e., as being within compliance). However, an interval of $20 \pm 4$ days between the first and second injections, likely results in higher trough levels after the first dose, offering better protection against the virus [28]. Therefore, an interval of 16-35 days between the first and second injections was considered compliant.

Comparative data from international registries was obtained through a search of Web of Science, PubMed, Medline, CINAHL, Cochrane, DARE, and OVID databases, using the key words "registry" AND "RSV" OR "respiratory syncytial virus" AND "newborn" OR "neonatal" OR "infantnewborn” AND “infant” AND "prophylaxis” OR "palivizumab". All identified reports were compiled based on the aforementioned criteria and were further checked for references regarding additional pertinent studies, and a nucleus of key articles was derived for analyses (Figure 1).

\section{Statistical Analysis}

CARESS data were examined using standard descriptive methods. Data was entered into SPSS v20.0 (SPSS Inc, Chicago, Illinois) for analysis. The primary endpoint of this observational study was hospitalization. The RIH rate was defined as the number of children hospitalized for a respiratory-related illness/total number of children who received palivizumab. The RSVH rate was calculated using the formula: $\mathrm{RIH} \times$ the number of RSV-positive children/the number of children with a respiratory illness tested. The characteristics of hospitalized versus nonhospitalized patients were evaluated to identify potential risk factors for respiratory illness-related hospitalization. The statistical tests used to determine these factors included Student's $t$-test and analysis of variance (ANOVA) for continuous variables and Pearson's chi-square $\left(\chi^{2}\right)$ test for nominal variables. An ANOVA was also applied in place of Student's $t$-test when more than two groups were assessed. A $P$ value of $<0.05$ was considered statistically significant.

To determine any factors that may affect time to RSVH, a Cox proportional hazards analysis was conducted using a backwards conditional method. Patients were followed for up to 30 days after their final injection. Results are presented in terms of hazard ratios (HR), with 95\% confidence intervals (95\% CI).

\section{Results}

A total of 13,310 patients were recruited across 32 sites since the 2005-2006 RSV season. The proportions of patients recruited for the CARESS study are representative of the population proportions found by Statistics Canada in their 


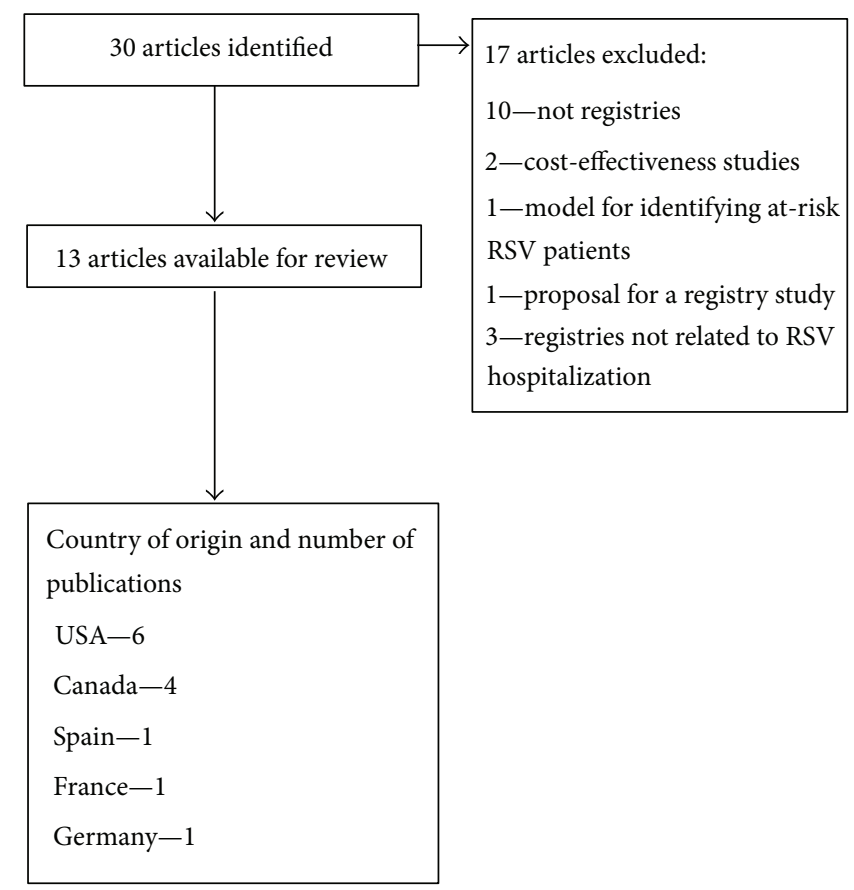

FIGURE 1: Flow chart of assembled articles from the scientific literature.

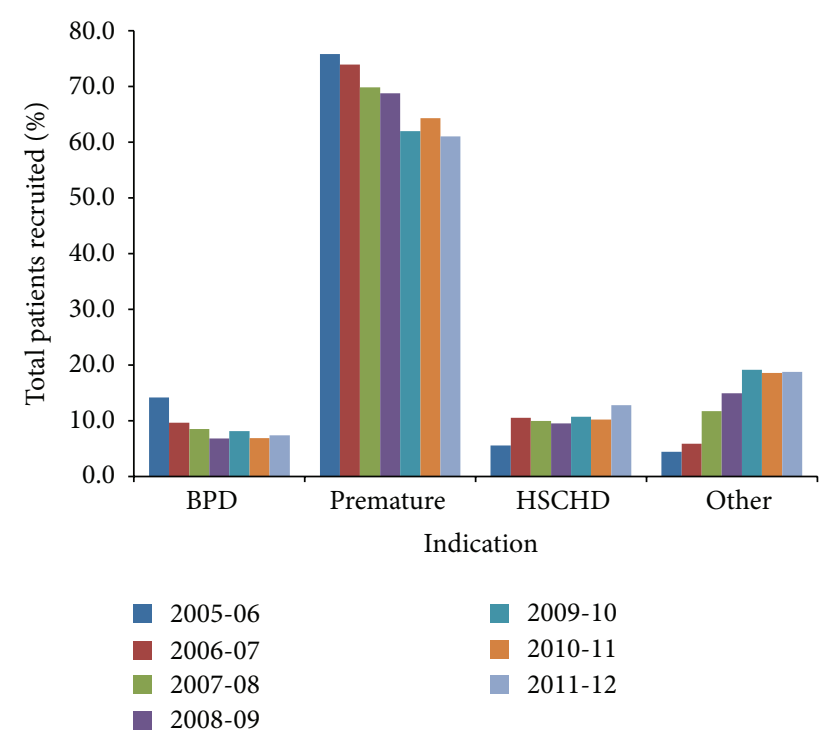

FIgURe 2: Palivizumab indications across seasons. Indications are subcategorized into chronic lung disease (BPD/CLD, $n=1048$ ), premature ( $n=8751)$, hemodynamically significant congenital heart disease (HSCHD, $n=1414)$, and "other" $(n=2097)$. The "other" group comprises infants with serious underlying medical disorders.

latest quarterly demographic estimates [29]. Over the 7 years, $65.7 \%$ of patients prophylaxed with palivizumab were premature, $7.9 \%$ had CLD only and were not classified in any other category, $10.6 \%$ had HSCHD, and $15.8 \%$ had "other" serious medical disorders. Figure 2 shows the distribution of patients based on indication for prophylaxis from 2005 to 2012 . Table 1 compares demographics across the indications. There were statistically significant differences between the groups in percent Caucasians, mean birth weight, enrolment and gestational age, daycare attendance, family history of atopy, multiple births, household smoking and more than 2 smokers in the home, siblings, siblings in daycare, and $>5$ people in the household. A post hoc analysis was conducted using the Tukey test to determine which indications contributed to the statistical significance. Birth weight across all indications was statistically significantly different from the "other" subcategory $(P<0.05)$. With regard to enrolment weight, the premature group was significantly different from the other 3 indications (CLD, HSCHD, and "other"; $P<0.005$ ), while the HSCHD and "other" groups were similarly significantly different $(P<$ 0.05). For gestational age, with the exception of the CLD and premature groups $(P=0.953)$, the indications were all significantly different from each other $(P<0.05)$. Over the seven RSV seasons encompassed by CARESS, there has been a 4.3 -fold increase in the percentage of patients recruited that have been prophylaxed for serious underlying medical disorders, from $4.4 \%$ in the $2005-2006$ RSV season to $18.8 \%$ in the 2011-2012 RSV season. Within the "other" category, there has also been a change in the distribution of recruitment in each subcategory (Table 2). More than $>50 \%$ of the patients comprise the miscellaneous subcategory, which suggests that overall greater numbers of patients are receiving "off-label" palivizumab because of their illness severity.

More than $50 \%$ of the patients received respiratory support $(59.4 \%)$ and oxygen therapy $(52.6 \%)$ during the neonatal period. The average \pm standard deviation duration of respiratory support was $23.3 \pm 35.8$ days, and the average duration of oxygen therapy was $37.5 \pm 64.9$ days. The average length of hospital stay after birth was $50.6 \pm 80.8$ days. Not surprisingly, significantly higher percentages of premature 
TABLE 1: Cumulative patient demographics by prophylaxis indication (2005-2012).

\begin{tabular}{|c|c|c|c|c|c|c|}
\hline & $\begin{array}{c}\text { Premature } \\
N=8751\end{array}$ & $\begin{array}{c}\text { CLD } \\
N=1048\end{array}$ & $\begin{array}{c}\text { HSCHD } \\
N=1414\end{array}$ & $\begin{array}{c}\text { Other } \\
N=2097\end{array}$ & $\begin{array}{c}\text { Total } \\
N=13310\end{array}$ & $P$ value \\
\hline Male, $n(\%)$ & $4996(57.1)$ & $601(57.3)$ & $777(55.0)$ & $1161(55.4)$ & $7535(56.6)$ & 0.280 \\
\hline Caucasian, $n(\%)$ & $6031(68.9)$ & $750(71.6)$ & $1047(74.0)$ & $1538(73.3)$ & $9366(70.4)$ & $<0.0005$ \\
\hline Daycare attendance, $n(\%)$ & $107(1.2)$ & $58(5.5)$ & $117(8.3)$ & $196(9.3)$ & $478(3.6)$ & $<0.0005$ \\
\hline Atopy in the family, $n(\%)$ & $3390(38.7)$ & $471(44.9)$ & $610(43.1)$ & $920(43.9)$ & $5391(40.5)$ & $<0.0005$ \\
\hline Mean enrolment age $(\mathrm{mo} \pm \mathrm{SD})$ & $3.3 \pm 3.1$ & $10.3 \pm 7.3$ & $8.7 \pm 7.3$ & $10.0 \pm 8.9$ & $5.5 \pm 6.2$ & $<0.0005$ \\
\hline Mean gestational age $(w k \pm S D)$ & $30.9 \pm 3.3$ & $30.5 \pm 5.8$ & $38.1 \pm 10.6$ & $35.6 \pm 5.7$ & $32.4 \pm 5.8$ & $<0.0005$ \\
\hline Mean birth weight $(g \pm S D)$ & $1590 \pm 632$ & $1628 \pm 1132$ & $3048 \pm 1154$ & $2583 \pm 1390$ & $1902 \pm 1043$ & $<0.0005$ \\
\hline Mean enrolment weight $(g \pm S D)$ & $4017 \pm 2167$ & $7047 \pm 2510$ & $6092 \pm 4423$ & $7258 \pm 3257$ & $5082 \pm 3087$ & $<0.0005$ \\
\hline Multiple births, $n(\%)$ & $3140(35.9)$ & $250(23.9)$ & $89(6.3)$ & $340(16.2)$ & $3819(28.7)$ & $<0.0005$ \\
\hline Mother that smokes, $n(\%)$ & $1259(14.4)$ & $163(15.6)$ & $197(13.9)$ & $260(12.4)$ & $1879(14.1)$ & 0.067 \\
\hline Mother smoked during pregnancy, $n(\%)$ & $1193(13.6)$ & $151(14.4)$ & $184(13.0)$ & $252(12.0)$ & $1780(13.4)$ & 0.188 \\
\hline Smoking in the household, $n(\%)$ & $2471(28.2)$ & $276(26.3)$ & $335(23.7)$ & $465(22.2)$ & $3547(26.6)$ & $<0.0005$ \\
\hline$\geq 2$ smokers in the home, $n(\%)$ & $979(11.2)$ & $101(9.6)$ & $138(9.8)$ & $198(9.4)$ & $1416(10.6)$ & 0.042 \\
\hline Siblings, $n(\%)$ & $5384(61.5)$ & $658(62.8)$ & $791(55.9)$ & $1364(65.0)$ & $8197(61.6)$ & $<0.0005$ \\
\hline Siblings in daycare, $n(\%)$ & $1588(18.1)$ & $153(14.6)$ & $242(17.1)$ & $451(21.5)$ & $2434(18.3)$ & $<0.0005$ \\
\hline$\geq 5$ people in the household, $n(\%)$ & $2509(28.7)$ & $238(22.7)$ & $299(21.1)$ & $505(24.1)$ & $3551(26.7)$ & $<0.0005$ \\
\hline
\end{tabular}

HSCHD: hemodynamically significant congenital heart disease; CLD: chronic lung disease.

TABLE 2: Changing patient profiles in the subcategory "other" over 6 RSV seasons*.

\begin{tabular}{|c|c|c|c|c|c|c|}
\hline \multirow[b]{2}{*}{ Indication, $n(\%)$} & \multicolumn{6}{|c|}{ RSV Season } \\
\hline & $\begin{array}{c}2006-2007 \\
N=72\end{array}$ & $\begin{array}{c}2007-2008 \\
N=169\end{array}$ & $\begin{array}{c}2008-2009 \\
N=298\end{array}$ & $\begin{array}{c}2009-2010 \\
N=462\end{array}$ & $\begin{array}{c}2010-2011 \\
N=511\end{array}$ & $\begin{array}{c}2011-2012 \\
N=538\end{array}$ \\
\hline Down syndrome & $2(2.8)$ & $47(27.8)$ & $62(20.8)$ & $81(17.5)$ & $107(20.9)$ & $150(27.9)$ \\
\hline Cystic fibrosis & $13(18.1)$ & $19(11.2)$ & $28(9.4)$ & $55(11.9)$ & $54(10.6)$ & $52(9.7)$ \\
\hline Congenital airway anomaly & $16(22.2)$ & $46(27.2)$ & $50(16.8)$ & $66(14.3)$ & $91(17.8)$ & $75(13.9)$ \\
\hline Miscellaneous & $41(56.9)$ & $57(33.7)$ & $158(53)$ & $260(56.3)$ & $259(50.7)$ & $261(48.5)$ \\
\hline Pulmonary disorders & $13(18.1)$ & $12(7.1)$ & $65(21.8)$ & $90(19.5)$ & $89(17.4)$ & $73(13.6)$ \\
\hline Neuromuscular impairment & $12(16.7)$ & $11(6.5)$ & $15(5.0)$ & $40(8.7)$ & $40(7.8)$ & $35(6.5)$ \\
\hline Immunocompromised & $1(1.4)$ & $3(1.8)$ & $4(1.3)$ & $9(1.9)$ & $9(1.8)$ & $24(4.5)$ \\
\hline Cardiac disease $\geq 2 \mathrm{yr}$ & $0(0.0)$ & $7(4.1)$ & $7(2.3)$ & $7(1.5)$ & $10(2.0)$ & $11(2.0)$ \\
\hline Multisystem anomalies & $5(6.9)$ & $6(3.6)$ & $32(10.7)$ & $15(3.2)$ & $30(5.9)$ & $41(7.6)$ \\
\hline Various medical disorders & $10(13.9)$ & $18(10.7)$ & $35(11.7)$ & $99(21.4)$ & $81(15.9)$ & $77(14.3)$ \\
\hline
\end{tabular}

${ }^{*}$ The 2005-2006 season was excluded as this information was not collected sequentially in all the subcategories for that year.

and CLD patients received respiratory support than HSCHD and "other" indications (63.8\% and $76.1 \%$ versus $40.2 \%$ and $45.9 \%$ ). Compared to HSCHD and "other" indications significantly higher percentages of subjects in the CLD group received oxygen therapy $(84.7 \%$ versus $44.8-52.6 \%)$ and had documented necrotizing enterocolitis (6.4\% versus $2.0-$ $3.3 \%$ ), sepsis (30.9\% versus $8.9-14.8 \%$ ), and surgery for patent ductus arteriosus (19.9\% versus 3.6-6.6\%).

4.1. Palivizumab Utilization. Overall, patients received $98.2 \% \pm 32.1 \%$ of their expected injections. Using inter-dose intervals, overall, $73.2 \%$ of infants were compliant. The 2006-07 season had a lower percentage of compliant subjects compared to other years $(60.9 \%$ versus $67.8 \%-79.8 \%, P<$ 0.00005).
4.2. Hospitalizations for Respiratory Illness-Related Events. Of the 13,310 patients that have been enrolled into the CARESS study, 875 patients had a total of 1,022 hospitalizations for a respiratory illness, giving a hospitalization rate of $6.6 \%$. Patients were hospitalized for a range from 0 to 6 episodes per season. The average length of hospital stay was $8.8 \pm 17.2$ days with an average of $1.9 \pm 8.9$ days in intensive care. There may be an emerging trend towards higher hospitalization rates, with a low of 3.3\% (2005-2006) and a high of 7.7\% (2010-11) but with some variation (Figure 3 ).

Reviewing hospitalizations by indication (Table 3), a lower proportion of hospitalized versus nonhospitalized patients were premature $(43.9 \%$ versus $67.3 \%, P<0.0005)$ with a higher proportion $\leq 28$ completed weeks GA $(16.6 \%$ versus $14.5 \%)$. Conversely, there were a significantly higher 
TABLE 3: Hospitalized versus nonhospitalized patients for respiratory-related illness based on indication.

\begin{tabular}{|c|c|c|c|}
\hline Indication & $\begin{array}{c}\text { Hospitalized (\%) } \\
\quad N=875\end{array}$ & $\begin{array}{l}\text { Not hospitalized (\%) } \\
\quad N=12435\end{array}$ & $P$ value $\left(\chi^{2}\right)$ \\
\hline Premature & $384(43.9)$ & $8367(67.3)$ & $<0.0005$ \\
\hline$\leq 28$ weeks GA & $145(16.6)$ & $1805(14.5)$ & 0.101 \\
\hline 29-32 weeks GA & $175(20.0)$ & $4645(37.4)$ & $<0.0005$ \\
\hline 33-35 weeks GA & $64(7.3)$ & $1902(15.3)$ & $<0.0005$ \\
\hline CLD & $128(14.6)$ & $920(7.4)$ & $<0.0005$ \\
\hline HSCHD & $146(16.7)$ & $1268(10.2)$ & $<0.0005$ \\
\hline Other & $217(24.8)$ & $1880(15.1)$ & $<0.0005$ \\
\hline Neuromuscular disorders & $28(3.2)$ & $125(1.0)$ & $<0.0005$ \\
\hline Airway anomaly & $45(5.1)$ & $299(2.4)$ & $<0.0005$ \\
\hline Cystic fibrosis & $9(1.0)$ & $222(1.8)$ & 0.115 \\
\hline Down syndrome & $38(4.3)$ & $411(3.3)$ & 0.096 \\
\hline Pulmonary & $37(4.2)$ & $309(2.5)$ & 0.003 \\
\hline Cardiac $\geq 2$ years & $4(0.5)$ & $38(0.3)$ & 0.355 \\
\hline Immunocompromised & $9(1.0)$ & $41(0.3)$ & 0.005 \\
\hline Multisystem anomalies & $18(2.1)$ & $113(0.9)$ & 0.004 \\
\hline Various medical disorders & $29(3.3)$ & $322(2.6)$ & 0.188 \\
\hline
\end{tabular}

HSCHD: hemodynamically significant congenital heart disease; CLD: chronic lung disease.

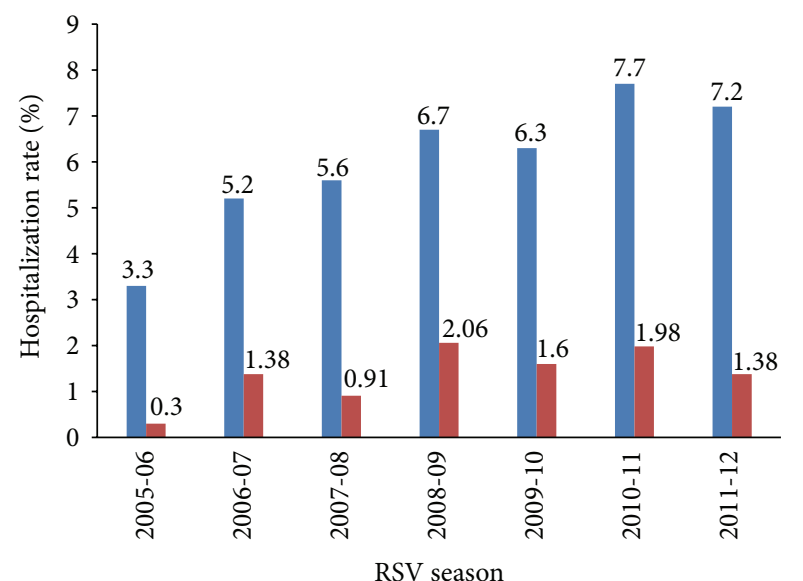

- Respiratory illness hospitalizations

- RSV-positive hospitalizations

FIGURE 3: Hospitalizations for respiratory-related illness and RSVpositive infection (2005-2012).

proportion of hospitalized patients in each of the other indication groups than nonhospitalized patients apart from cystic fibrosis. However, no significant differences were found between hospitalized and nonhospitalized patients in terms of the proportion that had Down syndrome $(P=0.096)$, cystic fibrosis $(P=0.115)$, cardiac problems $(P=0.355)$ and various medical disorders $(P=0.188)$.

Comparing demographic information between hospitalized and nonhospitalized patients, a greater proportion attended daycare $(5.8 \%$ versus $3.4 \%, P<0.0005)$ and had siblings that attended daycare $(26.2 \%$ versus $17.7 \%, P<$ 0.0005). Hospitalized infants also had more exposure to smoking, specifically, having a mother that smoked (19.1\% versus $13.8 \%, P<0.0005)$, a mother that smoked during pregnancy $(18.4 \%$ versus $13.0 \%, P<0.0005)$, smokers at home $(32.2 \%$ versus $26.3 \%, P<0.0005)$, and more than 2 smokers at home ( $13.6 \%$ versus $10.4 \%, P=0.004)$. While a greater proportion of hospitalized infants had siblings (71.8\% versus $60.9 \%, P<0.0005)$, a lower proportion were from multiple births (20.8\% versus $29.2 \%, P<0.0005)$. A greater proportion of hospitalized infants also had a history of atopy in their immediate family ( $47.1 \%$ versus $40.0 \%, P<0.0005$ ).

Analyzing hospitalizations in terms of palivizumab compliance showed no significant difference between hospitalized and nonhospitalized patients in terms of compliance by expected number of injections $(63.8 \%$ versus $66.2 \%, P=$ $0.149)$. However, based on interdose intervals, a significantly lower proportion of hospitalized patients were compliant with treatment $(67.8 \%$ versus $73.6 \%, P<0.0005)$. On average, hospitalized infants received a statistically greater number of injections than nonhospitalized infants (4.4 versus $4.2, P<$ 0.0005). There was no significant difference between the two groups in terms of the number of days between infants' first and second injections (28.8 versus 28.0 days, $P=0.149$ ).

4.3. RSV-Related Hospitalizations. Of the 13,310 patients enrolled, 875 patients had a total of 1,022 RIHs. Among these, 847 RSV diagnostic tests were performed on 733 patients, predominantly using a nasal swab $(30.6 \%)$ or a nasal aspirate $(61.4 \%)$ and $28(3.3 \%)$ were unreported. Of the 847 tests conducted, 177 (20.9\%) were found to be positive in 173 patients. The RSV-positive hospitalization rate was $1.55 \%$ $([875 / 13310] \times[173 / 733])$.

On review of the 7 RSV seasons, the RSV-positive hospitalization rate (Figure 3 ) has fluctuated from $0.30 \%$ (2005$2006)$ to $2.06 \%$ (2008-2009). With regard to demographic data, a greater proportion of infants hospitalized with RSV 
TABLE 4: Respiratory illness (RIH) and RSV-related hospitalization (RSVH) rates and morbidities encountered during hospital stay according to indication.

\begin{tabular}{|c|c|c|c|c|c|}
\hline & Prematurity & CLD & HSCHD & Other & $P$ value \\
\hline \multicolumn{6}{|l|}{ RIH } \\
\hline RIH rate & $4.4 \%$ & $12.2 \%$ & $10.3 \%$ & $10.3 \%$ & $<0.0005$ \\
\hline Length of stay $($ mean $\pm \mathrm{SD})$ & $7.9 \pm 14.8$ & $9.9 \pm 25.0$ & $8.7 \pm 10.9$ & $9.8 \pm 18.3$ & 0.469 \\
\hline Length of ICU stay (mean \pm SD) & $1.5 \pm 4.8$ & $1.7 \pm 6.9$ & $2.3 \pm 5.7$ & $2.5 \pm 14.7$ & 0.494 \\
\hline Days of intubation (mean $\pm S D$ ) & $0.7 \pm 3.0$ & $1.2 \pm 6.6$ & $0.9 \pm 3.4$ & $1.2 \pm 8.9$ & 0.643 \\
\hline Days of respiratory support (mean $\pm \mathrm{SD})$ & $1.4 \pm 4.8$ & $2.4 \pm 7.3$ & $1.8 \pm 5.2$ & $3.1 \pm 14.9$ & 0.117 \\
\hline \multicolumn{6}{|l|}{ RSVH } \\
\hline RSVH rate & $1.36 \%$ & $1.64 \%$ & $2.05 \%$ & $2.03 \%$ & $<0.0005$ \\
\hline Length of stay (mean \pm SD) & $7.7 \pm 10.3$ & $10.1 \pm 11.4$ & $7.2 \pm 7.7$ & $7.2 \pm 5.8$ & 0.776 \\
\hline Length of ICU stay (mean \pm SD) & $1.2 \pm 2.6$ & $3.1 \pm 11.8$ & $2.6 \pm 5.0$ & $1.6 \pm 4.0$ & 0.346 \\
\hline Days of intubation (mean $\pm S D$ ) & $0.6 \pm 2.0$ & $3.1 \pm 11.8$ & $1.6 \pm 3.3$ & $1.1 \pm 3.3$ & 0.180 \\
\hline Days of respiratory support (mean $\pm \mathrm{SD})$ & $1.2 \pm 2.7$ & $3.6 \pm 11.7$ & $2.1 \pm 4.7$ & $2.1 \pm 4.3$ & 0.294 \\
\hline
\end{tabular}

CLD: chronic lung disease; HSCHD: hemodynamically significant congenital heart disease; ICU: intensive care unit.

infections had siblings (80.3\% versus $61.3 \%, P<0.0005)$, attended daycare $(8.7 \%$ versus $3.5 \%, P=0.001)$, and had siblings that attended daycare $(32.4 \%$ versus $18.1 \%, P<$ $0.0005)$. A greater proportion also had a history of atopy in their immediate family ( $50.9 \%$ versus $40.4 \%, P=0.006$ ) were more likely to have been exposed to smoking, either by having a mother that smoked (20.2\% versus $14.0 \%, P=0.024)$, a mother that smoked during pregnancy (19.7\% versus $13.3 \%$, $P=0.021)$, or smokers in the household (37.6\% versus $26.5 \%$, $P=0.001)$.

Table 4 shows the RIH and RSVH rates by indication with encountered morbidities during hospitalization. The RIH and RSVH rates ranged between $4.4 \%-12 \%$ and $1.36 \%-2.05 \%$, respectively, across the groups and were statistically different (both $P<0.0005$ ).

The average length of hospital and ICU (mean \pm SD) stay for the total group was $8.8 \pm 17.2$ and $1.9 \pm 8.9$ days, respectively.

4.4. Cox Proportional Hazards Regression. To determine factors that may affect time to RSVH, a Cox proportional hazards regression was conducted. The overall model was significant $\left(\chi^{2}=65.847, \mathrm{df}=5, P<0.0005\right)$ and showed that having siblings (Figure $4(\mathrm{a}))(\mathrm{HR}=2.1,95 \% \mathrm{CI} 1.4-3.3, P<$ $0.0005)$, smokers in the household (Figure $4(\mathrm{~b}))(\mathrm{HR}=1.8$, 95\% CI 1.3-2.5, $P<0.0005),>5$ individuals in the household (Figure 4(c)); $\mathrm{HR}=1.7,95 \% \mathrm{CI} 1.3-2.4, P=0.001$ ), attending daycare (Figure $4(\mathrm{~d}))(\mathrm{HR}=2.3,95 \% \mathrm{CI} 1.3-4.0, P=0.004)$, and number of injections received ( $\mathrm{HR}=0.9,95 \% \mathrm{CI} 0.8$ $1.0, P=0.032$ ) were significant predictors of hospitalization. Other possible risk factors such as gestational age $(P=0.233)$, history of atopy $(P=0.081)$, gender $(P=0.776)$, being part of a multiple birth $(P=0.845)$, and compliance with treatment $(P=0.538)$ were not significant predictors. Interestingly, the hazard ratios also increased with increasing number of risk factors experienced by any infant (Figure 5). Infants with all 4 risk factors were 9.5 times more likely to be hospitalized with an RSV infection than those that had none of the risk factors.
Table 5 compares the data derived from international registries [28, 30-41], in 5 countries (USA, Canada, Germany, France, and Spain) accumulated from 2002 to 2012. Table 6 outlines the RI and RSVH rates in various subpopulations of infants drawn from the respective registries versus the existing RCTs. Overall RIH rates for preterm infants $<35$ weeks GA and CLD patients ranged from $2.6 \%$ to $14.9 \%$ across studies while the corresponding RSVH rates inclusive of HSCHD were $0.2 \%-9.0 \%$. In the RCTs, the RSVH rates for the same subgroups ranged from $1.8 \%$ to $7.9 \%$. There was only one cystic fibrosis registry that found an adjusted HR for RSVH of 2.4 (95\% CI; 0.8-6.6).

\section{Discussion}

Cumulatively, a total of 13,310 patients have been enrolled in the CARESS study, with $56.6 \%$ of the population being male, $70.4 \%$ Caucasian, and the majority were premature ( $\leq 35$ completed weeks GA; 65.7\%). The CARESS registry is the largest, comprehensive database of infants who have most currently received palivizumab (2005-2012) compared to other international registries that have published data from 1998 to 2007 (Table 5). Through the seven seasons of CARESS, there has been a steady increase in the percentage of patients that were given palivizumab prophylaxis for reasons that are not specifically indicated by Health Canada. This increase perhaps reflects emerging scientific data and an increased awareness of the potential morbidities and associated mortality with medical conditions such as neuromuscular disorders, Down syndrome, congenital airway and pulmonary abnormalities, immunocompromise, and cystic fibrosis [10-12, 42-49].

The 13,310 patients recruited into the CARESS study were given a total of 55,523 injections of palivizumab. More than half the patients received at least 4 injections per season, with an overall average of $4.2 \pm 1.5$ injections per infant. Compliance was $73.2 \%$ using interdose interval, with patients receiving $98.2 \% \pm 32.1 \%$ of their expected injections. 


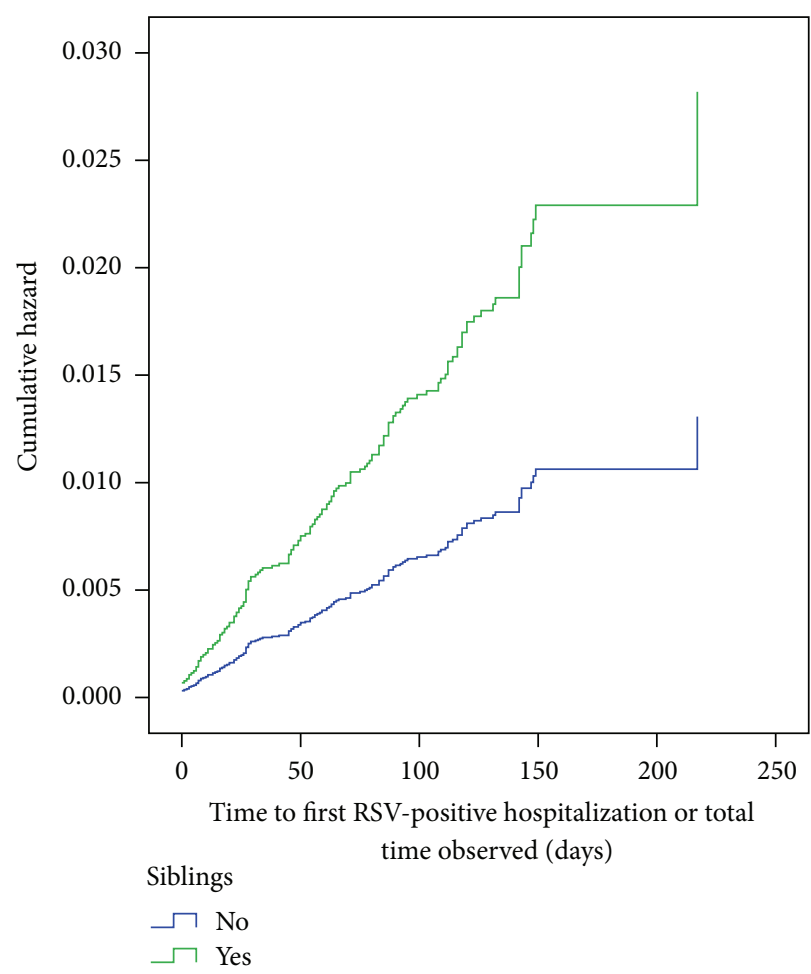

(a)

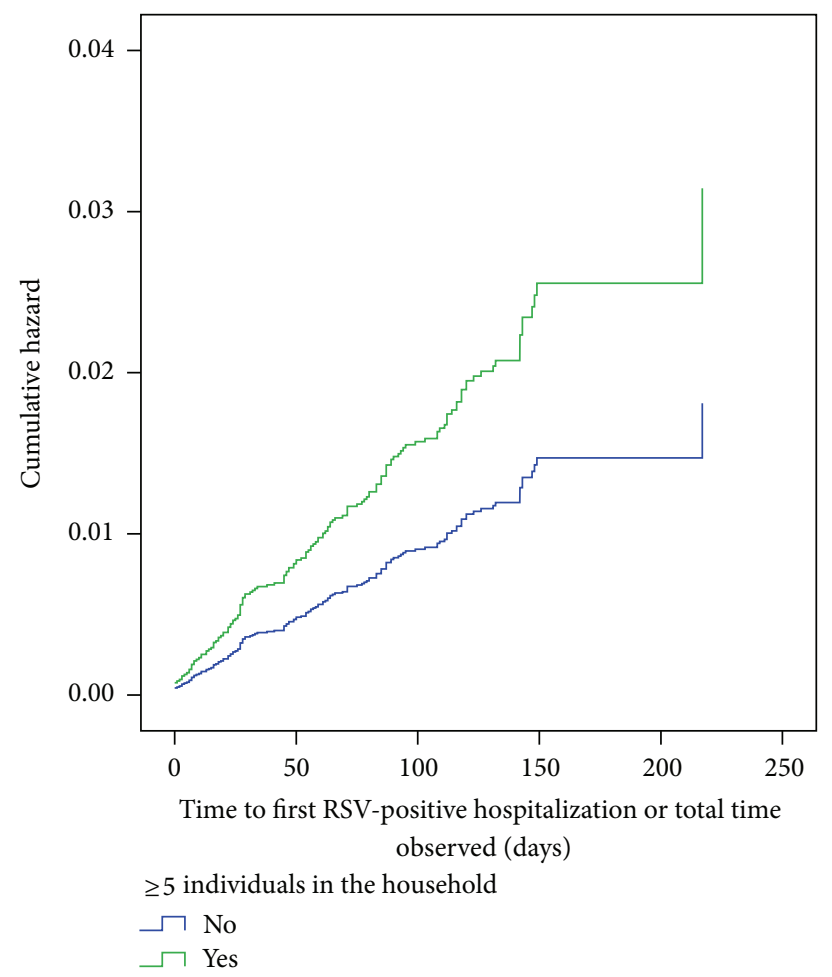

(c)

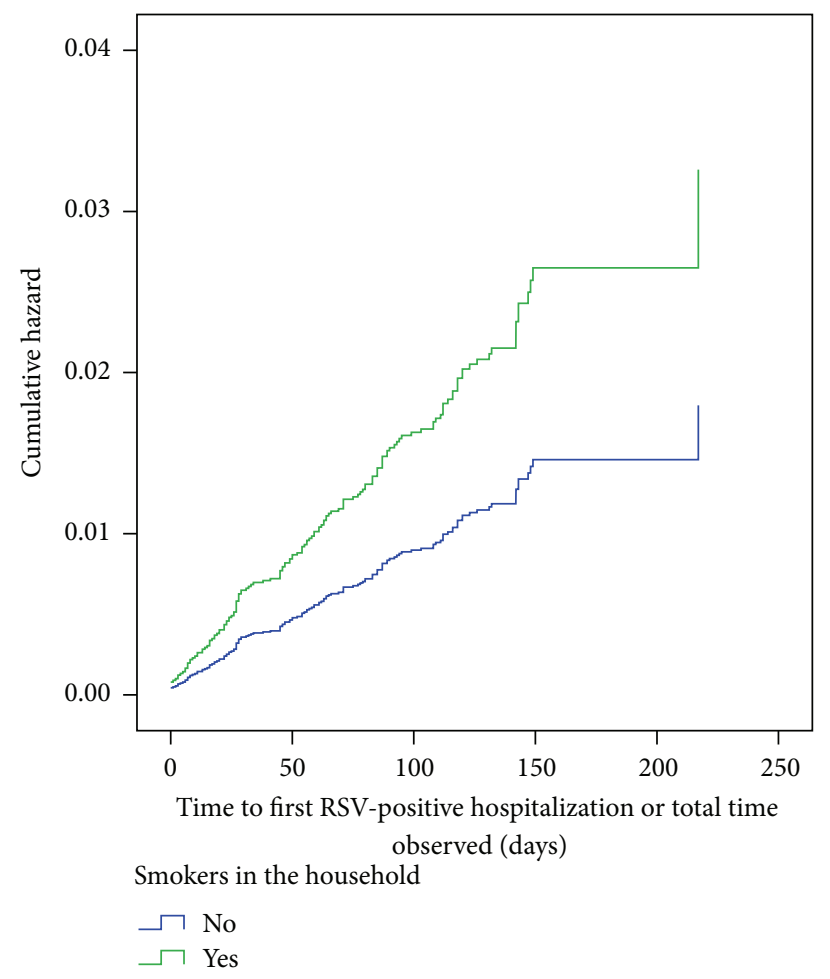

(b)

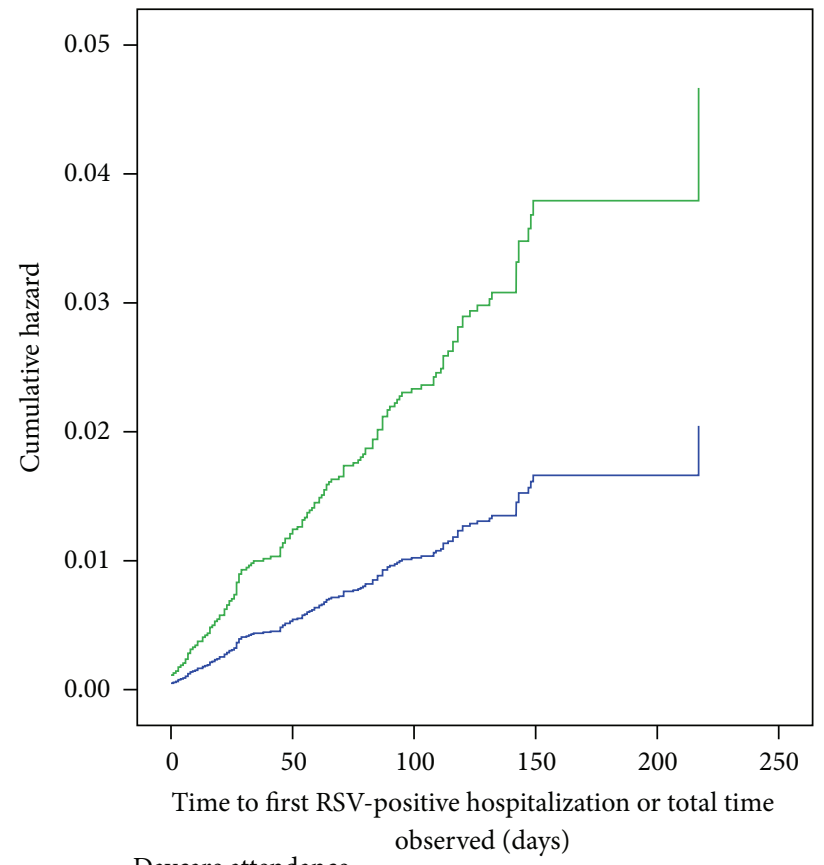

Daycare attendance

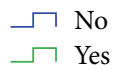

FIGURE 4: Hazard curves for the Cox proportional regression. (a) Comparing infants with siblings (green line) and those without (blue line). (b) Comparing infants with smokers in the household (green line) and those without (blue line). (c) Comparing infants with $\geq 5$ individuals in the household (green line) and those with $\leq 5$ members (blue line). (d) Comparing infants attending daycare (green line) versus nonattendees (blue line). 


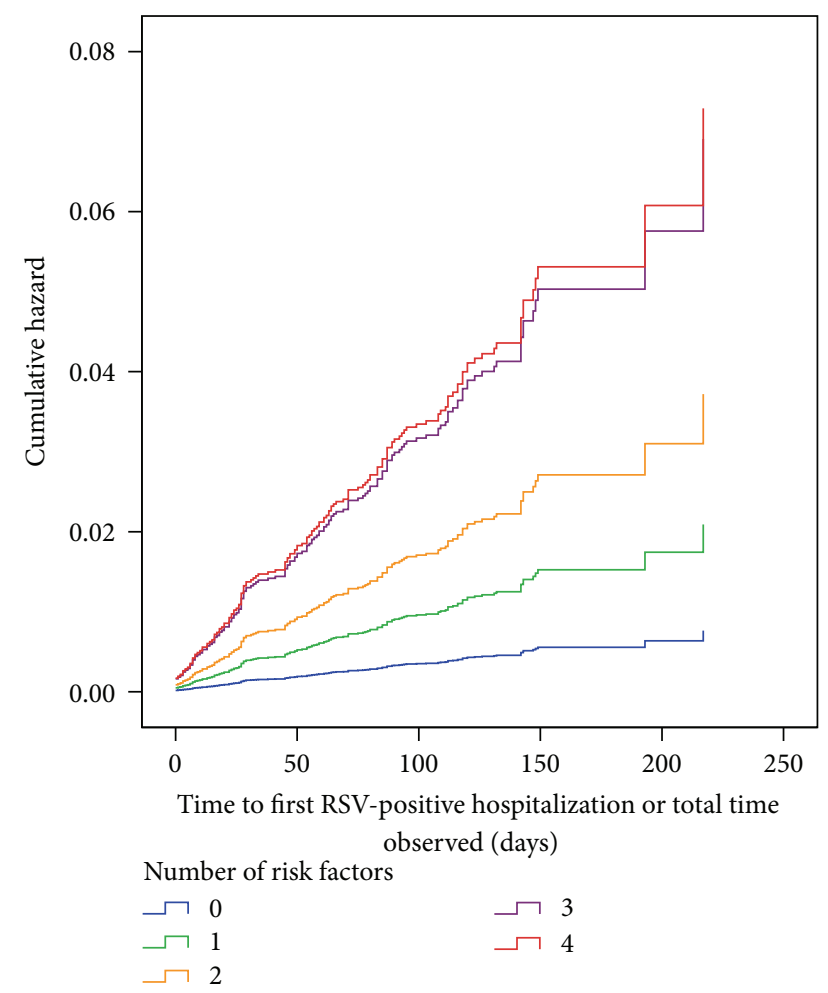

\begin{tabular}{c|c} 
Number of risk factors & HR $(95 \% \mathrm{CI})$ \\
\hline 0 & Baseline \\
1 & $2.7(1.5-5.1)$ \\
2 & $4.9(2.6-9.0)$ \\
3 & $9.0(4.6-17.6)$ \\
4 & $9.5(1.2-73.4)$ \\
\hline
\end{tabular}

FIGURE 5: Hazard curves for the Cox proportional regression based on the number of risk factors per infant. Risk factors included were siblings, smokers in the household, $\geq 5$ individuals in the household, and attending daycare.

875 patients were hospitalized a total of 1022 times for RIs within the CARESS registry, resulting in a hospitalization rate of $6.6 \%$. Palivizumab was designed to preferentially target RSV subtypes A and B and reduce related hospitalizations. Singleton et al. [50] described the outcomes of 335 high-risk, Alaska Native palivizumab recipients from 1998 to 2001. RSV hospitalizations occurred in 20.6\% (69/335), and 26.9\% were admitted with respiratory illnesses during the same period, confirming the selective effect of palivizumab against RSV. Across the registries, the RIH rates for prophylaxed premature infants and those with CLD ranged from $2.6 \%$ to $14.9 \%$ $[32,34,38,41]$, the highest being in infants with CLD $(10.5 \%-$ $14.9 \%)$ [34, 41]. Paes et al. [31], previously documented that following RSV prophylaxis, infants with complex medical disorders when compared to a healthy cohort $\leq 35$ weeks GA had an increased risk of RIH ( HR $=2.0,95 \%$ CI 1.5-2.5, $P<$ 0.0005 ) but not RSVH. Moreover the RIH rates varied from $3.4 \%$ in infants with cystic fibrosis to $17.9 \%$ for those with neuromuscular impairments. This substantiates the fact that children with serious, underlying conditions remain prone to sever illness with a broad spectrum of viral infections apart from RSV.

The cumulative CARESS (2005-2012) RSVH rate was $1.55 \%$, and this is within the range of other palivizumab outcome registries $(1.3 \%-8.1 \%)[28,33,37-39,41]$. The upper limit of $8.1 \%$ was found in the French registry [41], where the prevalence of CLD (81\%) was significantly higher compared to the other described cohorts. In general, the registries reported lower RSVH rates compared to the RCTs; CLD $(1.31 \%-5.8 \%)$ versus $7.9 \%$, infants $<32$ weeks $(1.5 \%-4.5 \%)$ versus $5.8 \%$, infants $32-35$ weeks $(0.2 \%-1.6 \%)$ versus $2.0 \%$, and HSCHD (1.99\%) versus 5.3\%, respectively. The US outcomes registry [37] documented steadily declining RSVH rates from $2000(2.9 \%)$ to $2004(0.7 \%)$ for all subjects, and $9.1 \%(n=1,123)$ had congenital airway anomalies or severe neuromuscular impairments. However, the CARESS database comprises 2,097 (15.8\%) patients with a spectrum of serious underlying medical disorders who have received palivizumab, and these infants are likely to have higher breakthrough RSVH rates following immunization, despite optimal adherence to dosing schedules $[15,16,31,36]$. Apart from striving to achieve $100 \%$ compliance, to further reduce $\mathrm{RSVH}$, another potential strategy that can be adopted is a home-based prophylaxis program [36]. However, operationalizing this concept is administratively demanding and needs to be proven as cost-effective.

Infants with cystic fibrosis like patients with bronchopulmonary dysplasia (CLD) may develop severe, acute illness with RSV. In CF, synergy between virus and bacteria may lead to repetitive bacterial exacerbations [51]. While the majority of pediatric advisory bodies have universally approved RSV prophylaxis for CLD, there remains active debate as to whether CF patients merit palivizumab [43, 45, 52, 53]. The US CF foundation $[54,55]$ recommends that RSV prophylaxis should be considered for CF patients based on estimated net benefit which was graded as moderate and was derived from the limited number of existing uncontrolled studies. In the absence of a completed RCT in this population [42], the only available CF registry data [28] also suggests a potential benefit for prophylaxis, but more conclusive evidence from larger studies is awaited.

The Cox proportional hazards analysis found that patients with siblings, those attending daycare, and who have either smokers or $\geq 5$ people in their household were at higher risk of an RSV-positive hospitalization, with hazard ratios increasing concurrently with an incremental increase in the number of risk factors. These factors have a well-established association with severe RSV lower respiratory tract infection [56, 57], and similar findings were identified in several of the registries [33, 35-40]. Interestingly, in CARESS, compliance with treatment based on the expected number of injections rather than interdose intervals was not found to be a predictor of time to first RSV-positive hospitalization. This result is identical to what was found in the Palivizumab Outcomes Registry [37] suggesting that perhaps more stringent control of the timing of individual doses is perhaps more beneficial in reducing RSVH. The number of RSVHs is also likely dependent on 


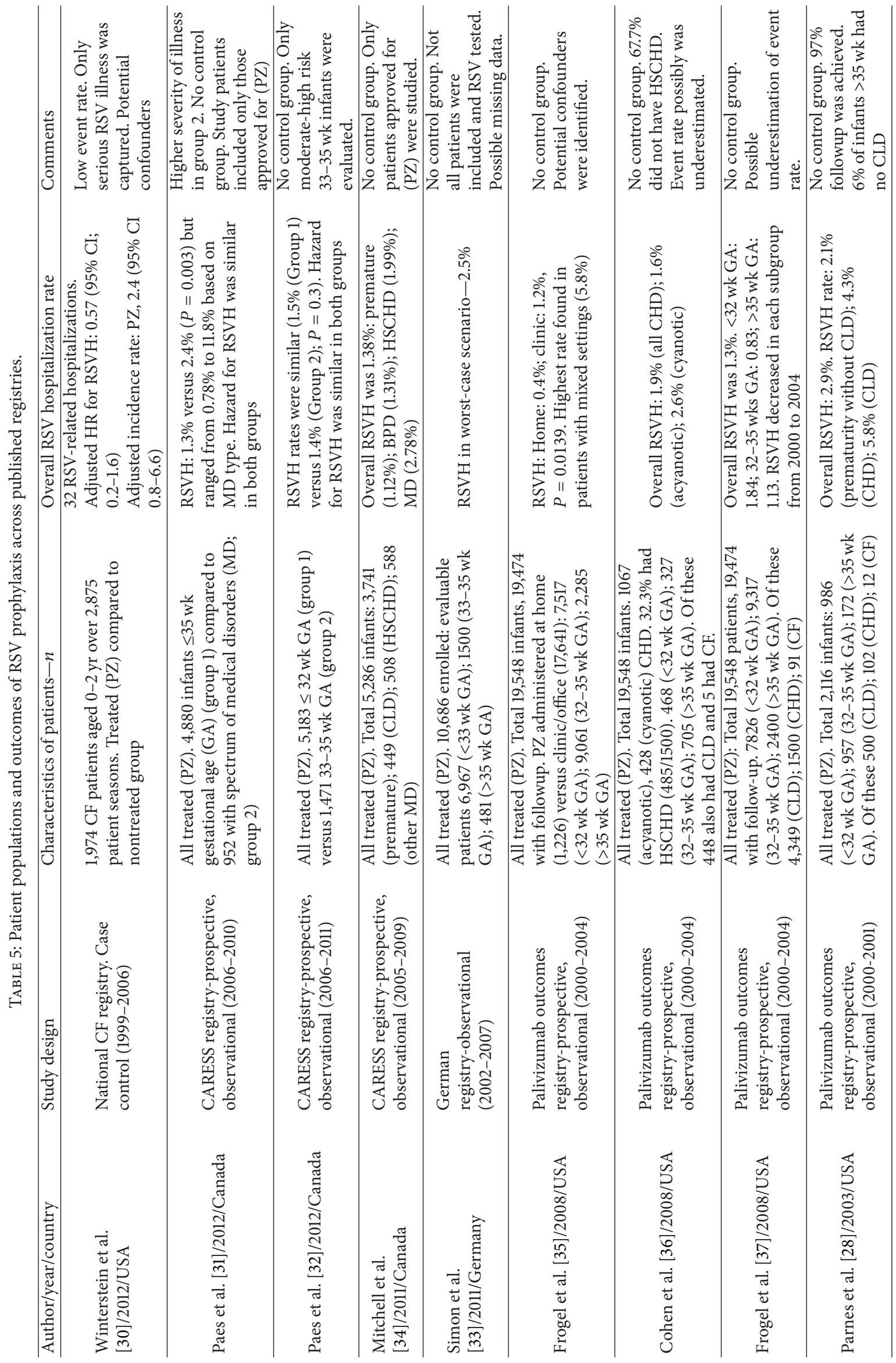




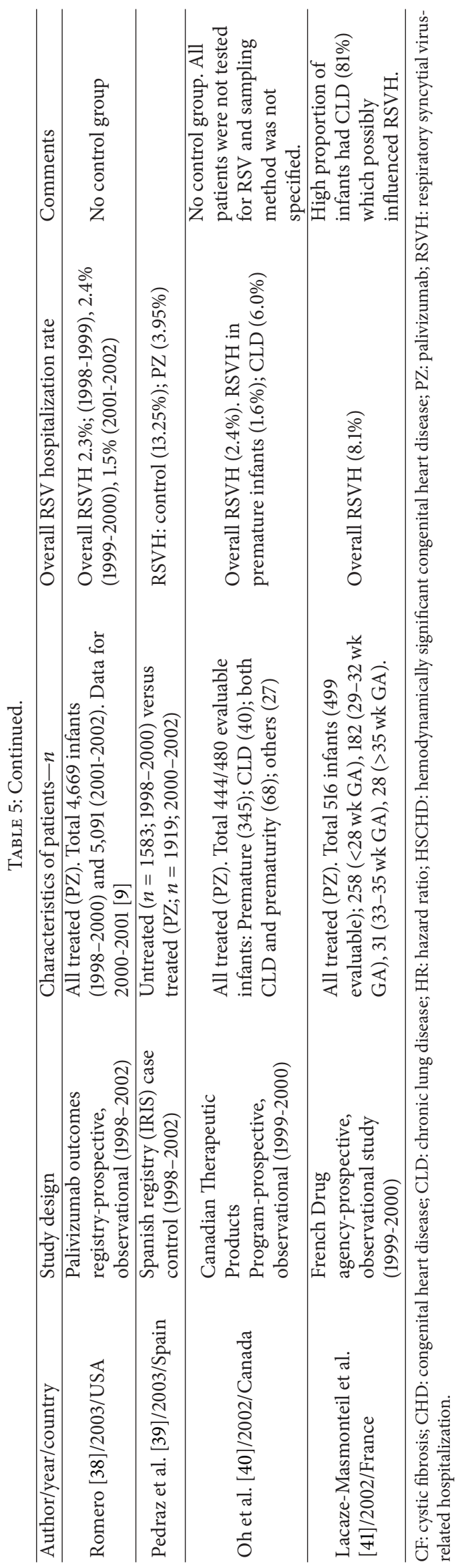




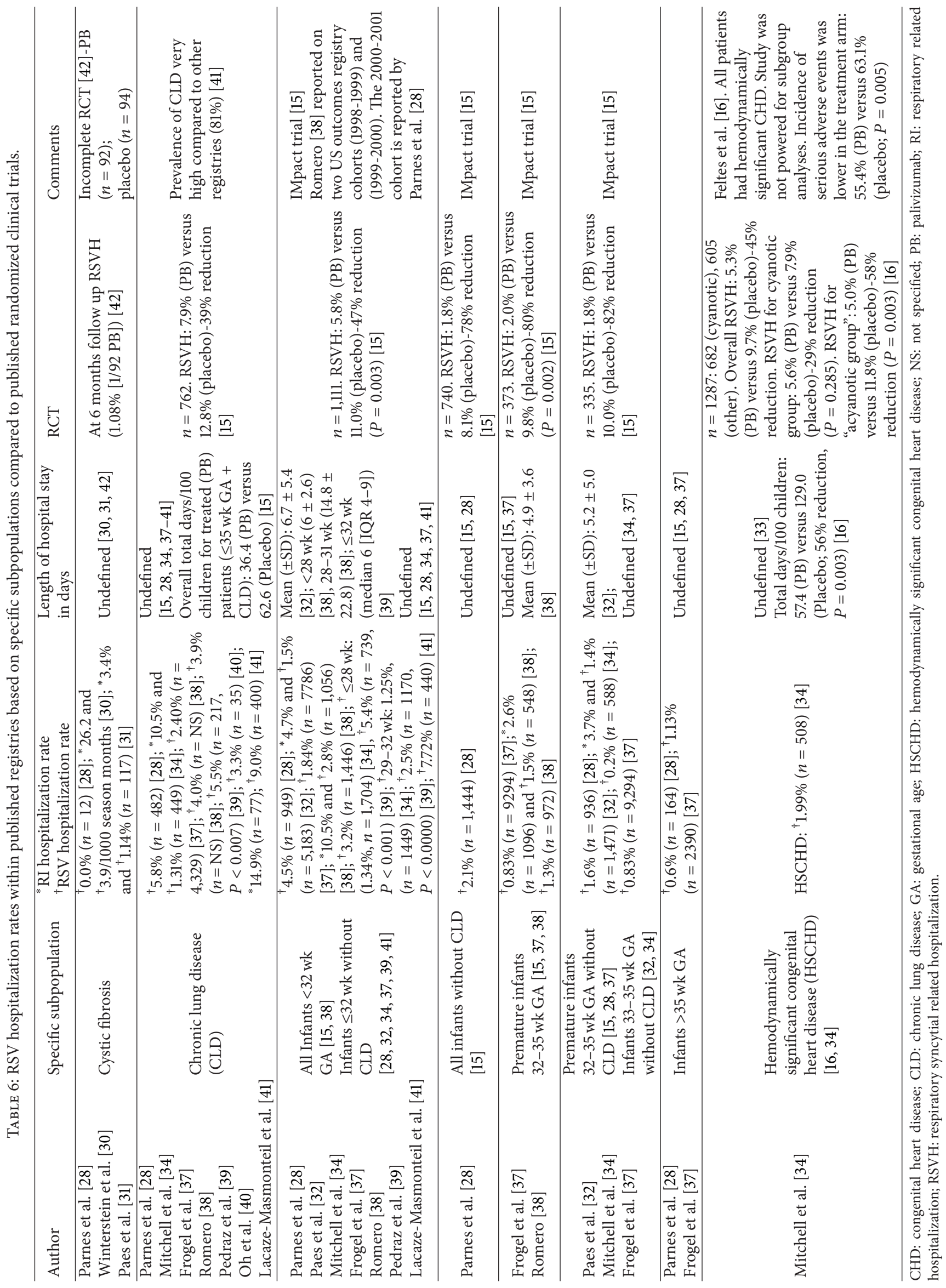


the pharmacokinetics of palivizumab $[15,16,26]$, with the highest frequency occurring between the first and second injection (range $31 \%-46 \%$ ) with steadily declining rates to approximately $10 \%$ between the 3 rd and 4 th dose $[28,37]$.

There are perhaps several reasons that may account for the decreasing rates of RSVH seen in the Palivizumab Outcomes Registry [37] compared to the current CARESS study and older studies such as COMPOSS (1999-2000) [40], Romero (1998-2002) [38], and the IMpact-RSV trial (19961997) [15]. Since the Palivizumab Outcomes Registry, which spanned the 2000-2004 RSV seasons, encompasses data that is, more recent, the lower RSVH rate may reflect changes in the health system, such as preventative education initiatives targeted at patients, improved compliance, variability in RSV epidemiology, and hospital admission criteria. The fact that the CARESS registry did not show a similar trend in RSVH rates may be explained by the increasing percentages of patients being tested for RSV with more precise diagnostic tests such as polymerase chain reaction and the steady increase in the prophylaxis of patients with complex disorders who are more likely to be hospitalized with RSV.

There are several limitations of this data that deserve mentioning. Registries are handicapped by the absence of a control arm which would help to more clearly delineate the true impact of RSV prophylaxis as documented in the RCTs $[15,16]$. Though the majority of assembled patients are similar because enrollment is founded on evidence-based local or national pediatric prophylaxis guidelines, variations do exist based on country-specific approval of populations such as 33-35 weeks GA infants and those patients with "off-label" medical, disorders for example, Down syndrome, neuromuscular impairments, and cystic fibrosis. However, the variance also facilitates new research endeavors especially in patients with complex medical disorders. RIH and RSVH detection rates are additionally influenced by the type of samples collected, the number and type of tests conducted, and the formula used for the standardization and reporting of results which were not always stated. Lastly, the changing demographic profile with varying levels of risk that contribute to RSV infection as in the Inuit population in the Canadian Arctic [58], term Alaska Native infants from the Yukon Delta [59], and the Aboriginal children in central Australia [60], combined with fluctuating epidemiological patterns of disease, may influence both RI and RSVH rates.

\section{Conclusions}

Over the past 15 years, palivizumab has been proven to be highly effective in decreasing RSVH rates, predominantly in children aged $<2$ years. The cumulative RIH and RSVH rates from 2005 to 2012 in the CARESS registry were $6.6 \%$ and $1.55 \%$, respectively, and these incidences align closely with the data from 5 international registries across 13 publications in the scientific literature. Overall RSVH rates from the registries, which reflect everyday use of palivizumab in clinical practice for the key subpopulations of prematurity, CLD, and HSCHD, are lower than in the two randomized trials. The CARESS database also indicates that over the seven RSV seasons there is a growing trend to prophylax patients with other serious medical conditions from $4.4 \%$ in $2005-2006$ to $18.8 \%$ in $2011-2012$. This 4.3 -fold increase indicates that pediatricians are strongly advocating for protection against serious RSV infection and possible sequelae in extremely high-risk patients. However, more evidence from well-conducted clinical trials is necessary before this strategy becomes standard of care for these infants.

\section{Conflict of Interests}

B. Paes, I. Mitchell, and K. L. Lanctôt have received investigator-initiated research funding from AbbVie Corporation and have been compensated as advisors and/or lecturers for AbbVie and MedImmune. I. Mitchell has received a research grant from Medimmune. A. Li has received a speaker's honorarium. T. Harimoto has no conflict of interests to declare. No honorarium, grant, or other form of payment was given to anyone to produce the paper.

\section{Acknowledgments}

The authors would like to thank the following CARESS investigators for their support during the 2005-2012 RSV seasons: Dr. Candice Bjornson, candice.bjornson@calgaryhealthregion.ca, Alberta Children's Hospital; Dr. Ian Mitchell, imitche@ucalgary.ca, Alberta Children’s Hospital; Dr. Mark Chilvers, mchilvers@cw.bc.ca, BC Children’s Hospital; Dr. Marc Lebel, marc_lebel@ssss.gouv.qc.ca, Centre Hospitalier de l'Université de Sainte-Justine; Dr. Mario Eddy Dumas, mario.eddy.dumas@usherbrooke.ca, Centre Hospitalier de l'Université de Sherbrooke; Dr. Georges Caouette, georges .caouette@crchul.ulaval.ca, Centre Hospitalier de l'Université de Laval; Dr. Charles Hui, chui@cheo.on.ca, Children's Hospital of Eastern Ontario; Dr. Ann Bayliss, abayliss@cvh .on.ca, Credit Valley Hospital; Dr. Bruno DiGravio, bruno.digravio@medportal.ca, Grand River Hospital; Dr. Jean-Pierre Doray, jpdoray@rocketmail.com, Hôpital Charles-LeMoyne; Dr. Dora Stinson, Dora.stinson@iwk.nshealth.ca, IWK Health Care; Dr. Apostolos Papageorgiou, apo.papageorgiou @mcgill.ca, Jewish General Hospital; Dr. Marianna Mitchell, drmarymitchell@rogers.com, Lakeridge Health Oshawa; Dr. David Lee, David.lee@lhsc.on.ca, London Health Sciences Centre; Dr. Aaron Chiu, achiu@exchange.hsc.mb.ca, Manitoba Institute of Child Health; Dr. Bosco Paes, paes@mcmaster.ca, McMaster Children's Hospital; Dr. Roderick Canning, rocannin@serha.ca, Moncton Hospital; Dr. Jesse Papenburg, jesse.papenburg@gmail.com, Montreal Children's Hospital; Dr. Karel O’Brien, kobrien@mtsinai.on.ca, Mount Sinai Hospital; Dr. Karen Chang, kdchang@rougevalley.ca, Rouge Valley Hospital; Dr. Koravangattu Sankaran, k.sankaran@ usask.ca, Royal University Hospital; Dr. Vincent Ho, byles.ho@rogers.com, Royal Victoria Hospital; Dr. Larry Chang, lchangnm@bellnet.ca, Southlake Regional Health Centre; Dr. Cecil Ojah, ojace@reg2.health.nb.ca, St. John Regional Hospital; Dr. Sanja Avdic, sa2412@aol.com, St. Joseph's Health Centre; Dr. Carina Majaesic, cmajaesi@cha .ab.ca, Stollery Children's Hospital; Dr. Marc Blayney, marc.blayney@normed.ca, Sudbury Regional Hospital; Dr. Brian Simmons, brian.simmons@sunnybrook.ca, 
Sunnybrook Health Sciences Centre; Dr. Jelena Popovich, Jpopo@tegh.on.ca, Toronto East General Hospital; Dr. Upton Allen, upton.allen@sickkids.ca, Toronto Hospital for Sick Children; Dr. Frank Jagdis, fjagdis@shaw.ca, Victoria General Hospital; Dr. Ivor Margolis, ivor_margolis@oslerhc.org, William Osler Health Centre; Dr. Godfrey Bacheyie, godfrey_bacheyie@wrh.on.ca, Windsor Regional Hospital.

\section{References}

[1] P. Mação, A. Dias, L. Azevedo et al., "Acute bronchiolitis: a prospective study," Acta Médica Portuguesa, vol. 24, supplement 2, pp. 407-412, 2011.

[2] F. A. Khamis, M. F. Al-Kobaisi, W. S. Al-Areimi et al., "Epidemiology of respiratory virus infections among infants and young children admitted to hospital in Oman," Journal of Medical Virology, vol. 84, no. 8, pp. 1323-1329, 2012.

[3] H. C. Moore, N. de Klerk, A. D. Keil et al., "Use of data linkage to investigate the aetiology of acute lower respiratory infection hospitalisations in children," Journal of Paediatrics and Child Health, vol. 48, no. 6, pp. 520-528, 2012.

[4] Y. Jin, R. F. Zhang, Z. P. Xie et al., "Newly identified respiratory viruses associated with acute lower respiratory tract infections in children in Lanzou, China, from 2006 to 2009," Clinical Microbiology and Infection, vol. 18, no. 1, pp. 74-80, 2012.

[5] W. Sánchez-Yebra, J. A. Ávila-Carrillo, F. Giménez-Sánchez et al., "Viral agents causing lower respiratory tract infections in hospitalized children: evaluation of the Speed-Oligo RSV assay for the detection of respiratory syncytial virus," European Journal of Clinical Microbiology \& Infectious Diseases, vol. 31, no. 3, pp. 243-250, 2012.

[6] C. C. Sung, H. Chi, N. C. Chiu et al., "Viral etiology of acute lower respiratory tract infections in hospitalized young children in Northern Taiwan," Journal of Microbiology, Immunology and Infection, vol. 44, no. 3, pp. 184-190, 2012.

[7] L. J. Stockman, A. T. Curns, L. J. Anderson et al., "Respiratory syncytial virus-associated hospitalizations among infants and young children in the United States, 1997-2006," The Pediatric Infectious Disease Journal, vol. 31, no. 1, pp. 5-9, 2012.

[8] C. B. Hall, "The burgeoning burden of respiratory syncytial virus among children," Infectious Disorders and Drug Targets, vol. 12, no. 2, pp. 92-97, 2012.

[9] C. B. Hall, G. A. Weinberg, M. K. Iwane et al., "The burden of respiratory syncytial virus infection in young children," The New England Journal of Medicine, vol. 360, no. 6, pp. 588-598, 2009.

[10] H. Nair, D. J. Nokes, B. D. Gessner et al., "Global burden of acute lower respiratory infections due to respiratory syncytial virus in young children: a systematic review and meta-analysis," The Lancet, vol. 375, no. 9725, pp. 1545-1555, 2010.

[11] R. C. Welliver Sr., P. A. Checchia, J. H. Bauman, A. W. Fernandes, P. J. Mahadevia, and C. B. Hall, "Fatality rates in published reports of RSV hospitalizations among high-risk and otherwise healthy children," Current Medical Research and Opinion, vol. 26, no. 9, pp. 2175-2181, 2010.

[12] D. Shefali-Patel, M. A. Paris, F. Watson et al., "RSV hospitalisation and healthcare utilisation in moderately prematurely born infants," European Journal of Pediatrics, vol. 171, no. 7, pp. 10551061, 2012.
[13] G. Ranmuthugala, L. Brown, and B. A. Lidbury, "Respiratory syncytial virus-the unrecognised cause of health and economic burden among young children in Australia," Communicable Diseases Intelligence, vol. 35, no. 2, pp. 177-184, 2011.

[14] S. Johnson, C. Oliver, G. A. Prince et al., "Development of a humanized monoclonal antibody (MEDI-493) with potent in vitro and in vivo activity against respiratory syncytial virus," Journal of Infectious Diseases, vol. 176, no. 5, pp. 1215-1224, 1997.

[15] IMpact-RSV Study Group, "Palivizumab, a humanized respiratory syncytial virus monoclonal antibody, reduces hospitalization from respiratory syncytial virus infection in high-risk infants," Pediatrics, vol. 102, no. 3 I, pp. 531-537, 1998.

[16] T. F. Feltes, A. K. Cabalka, H. C. Meissner et al., "Palivizumab prophylaxis reduces hospitalization due to respiratory syncytial virus in young children with hemodynamically significant congenital heart disease," Journal of Pediatrics, vol. 143, no. 4, pp. 532-540, 2003.

[17] E. A. F. Simoes and J. R. Groothuis, "Respiratory syncytial virus prophylaxis-the story so far," Respiratory Medicine B, vol. 96, supplement 2, pp. S15-S24, 2002.

[18] E. A. Simoes, "Immunoprophylaxis of respiratory syncytial virus: global experience," Respiratory Research, vol. 3, supplement 1, pp. S26-S33, 2002.

[19] J. L. Robinson, “Canadian Pediatric Society Infectious Diseases and Immunization Committee. Preventing respiratory syncytial virus infections," Paediatrics and Child Health, vol. 16, no. 8, pp. 488-490, 2011.

[20] B. Resch, A. Berger, G. Bernert et al., "Konsensuspapier zur prophylaxe der RSV-infektion mit palivizumab und post-RSVatemwegserkrankung," Monatsschrift Kinderheilkunde, vol. 156, pp. 381-383, 2008.

[21] J. Figueras-Aloy and X. Carbonell-Estrany, "Recommendations for the use of palivizumab in the prevention of respiratory syncytial virus infection in late preterm infants (32(1) to 35(0) weeks of gestation)," Anales de Pediatria, vol. 73, no. 2, pp. 98.el98.e4, 2010.

[22] American Academy of Pediatrics, "From the American Academy of Pediatrics: policy statements-modified recommendations for use of palivizumab for prevention of respiratory syncytial virus infections," Pediatrics, vol. 124, pp. 1694-1701, 2009.

[23] J. S. Sampalis, J. Langley, X. Carbonell-Estrany et al., "Development and validation of a risk scoring tool to predict respiratory syncytial virus hospitalization in premature infants born at 33 through 35 completed weeks of gestation," Medical Decision Making, vol. 28, no. 4, pp. 471-480, 2008.

[24] X. Sáez-Llorens, M. T. Moreno, O. Ramilo, P. J. Sánchez, F. H. Top, and E. M. Connor, "Safety and pharmacokinetics of palivizumab therapy in children hospitalized with respiratoy syncytial virus infection," The Pediatric Infectious Disease Journal, vol. 23, no. 8, pp. 707-712, 2004.

[25] K. N. S. Subramanian, L. E. Weisman, T. Rhodes et al., "Safety, tolerance and pharmacokinetics of a humanized monoclonal antibody to respiratory syncytial virus in premature infants and infants with bronchopulmonary dysplasia," The Pediatric Infectious Disease Journal, vol. 17, no. 2, pp. 110-115, 1998.

[26] G. J. Robbie, L. Zhao, J. Mondick et al., "Population pharmacokinetics of palivizumab, a humanized anti-respiratory syncytial virus monoclonal antibody, in adults and children," Antimicrobial Agents and Chemotherapy, vol. 56, no. 9, pp. 4927-4936, 2012. 
[27] B. J. Law, J. M. Langley, U. Allen et al., "The pediatric investigators collaborative network on infections in Canada study of predictors of hospitalization for respiratory syncytial virus infection for infants born at 33 through 35 completed weeks of gestation," The Pediatric Infectious Disease Journal, vol. 23, no. 9, pp. 806-814, 2004.

[28] C. Parnes, J. Guillermin, R. Habersang et al., "Palivizumab prophylaxis of respiratory syncytial virus disease in 20002001: results from the palivizumab outcomes registry," Pediatric Pulmonology, vol. 35, no. 6, pp. 484-489, 2003.

[29] Statistics Canada, "Table 051-0005-estimates of population, Canada, provinces and territories, quarterly (persons)," in: CANSIM (database), ed. 2012.

[30] A. G. Winterstein, E. Eworuke, D. Xu et al., "Palivizumab immunoprophylaxis effectiveness in children with cystic fibrosis," Pediatric Pulmonology, 2012.

[31] B. Paes, I. Mitchell, A. Li et al., "Respiratory hospitalizations and respiratory syncytial virus prophylaxis in special populations," European Journal of Pediatrics, vol. 171, no. 5, pp. 833-841, 2012.

[32] B. Paes, I. Mitchell, A. Li et al., "A comparative study of respiratory syncytial virus (RSV) prophylaxis in premature infants within the Canadian Registry of Palivizumab (CARESS)," European Journal of Clinical Microbiology \& Infectious Diseases, vol. 31, no. 10, pp. 2703-2711, 2012.

[33] A. Simon, H. Nowak, and R. Sterz, "Use of palivizumab in Germany: data from 2002-2007," Klinische Padiatrie, vol. 223, no. 5, pp. 292-298, 2011.

[34] I. Mitchell, B. A. Paes, A. Li et al., "CARESS: the Canadian registry of palivizumab," The Pediatric Infectious Disease Journal, vol. 30, no. 8, pp. 651-655, 2011.

[35] M. Frogel, C. Nerwen, M. Boron et al., "Improved outcomes with home-based administration of palivizumab: results from the 2000-2004 palivizumab outcomes registry," The Pediatric Infectious Disease Journal, vol. 27, no. 10, pp. 870-873, 2008.

[36] S. A. Cohen, R. Zanni, A. Cohen, M. Harrington, P. Vanveldhuisen, and M. L. Boron, "Palivizumab use in subjects with congenital heart disease: results from the 2000-2004 Palivizumab outcomes registry," Pediatric Cardiology, vol. 29, no. 2, pp. 382-387, 2008.

[37] M. Frogel, C. Nerwen, A. Cohen, P. VanVeldhuisen, M. Harrington, and M. Boron, "Prevention of hospitalization due to respiratory syncytial virus: results from the Palivizumab outcomes registry," Journal of Perinatology, vol. 28, no. 7, pp. 511$517,2008$.

[38] J. R. Romero, "Palivizumab prophylaxis of respiratory syncytial virus disease from 1998 to 2002: results from four years of palivizumab usage," The Pediatric Infectious Disease Journal, vol. 22, supplement 2, pp. S46-S54, 2003.

[39] C. Pedraz, X. Carbonell-Estrany, J. Figueras-Aloy, and J. Quero, "Effect of palivizumab prophylaxis in decreasing respiratory syncytial virus hospitalizations in premature infants," The Pediatric Infectious Disease Journal, vol. 22, no. 9, pp. 823-827, 2003.

[40] P. I. Oh, K. L. Lanctot, A. Yoon et al., "Palivizumab prophylaxis for respiratory syncytial virus in Canada: utilization and outcomes," The Pediatric Infectious Disease Journal, vol. 21, no. 6, pp. 512-518, 2002.

[41] T. Lacaze-Masmonteil, J. C. Rozé, and B. Fauroux, "Incidence of respiratory syncytial virus-related hospitalizations in high-risk children: follow-up of a national cohort of infants treated with Palivizumab as RSV prophylaxis," Pediatric Pulmonology, vol. 34, no. 3, pp. 181-188, 2002.
[42] A. H. Cohen, M. L. Boron, and C. Dingivan, "A phase IV study of the safety of synagis (Palivizumab) for prophylaxis of respiratory syncytial virus disease in children with cystic fibrosis," in Proceedings of the International Conference of the American Thoracic Society, Abstract A-53, San Diego, Calif, USA, May 2005.

[43] P. Manzoni, B. Paes, B. Resch et al., "High risk for RSV bronchiolitis in late preterms and selected infants affected by rare disorders: a dilemma of specific prevention," Early Human Development, vol. 88, supplement 2, pp. 34-41, 2012.

[44] B. Resch, P. Manzoni, and M. Lanari, "Severe respiratory syncytial virus (RSV) infection in infants with neuromuscular diseases and immune deficiency syndromes," Paediatric Respiratory Reviews, vol. 10, no. 3, pp. 148-153, 2009.

[45] B. Elnazir, O. Oni, T. Hassan et al., "Does prophylaxis with palivizumab reduce hospitalisation rates for respiratory-syncytial-virus-related infection in cystic fibrosis children less than 2 years of age?" Journal of Paediatrics and Child Health, vol. 48, no. 11, pp. 1033-1108, 2012.

[46] P. Zachariah, M. Ruttenber, and E. A. Simões, "Down syndrome and hospitalizations due to respiratory syncytial virus: a population-based study," Journal of Pediatrics, vol. 160, no. 5, pp. 827.el-831.el, 2012.

[47] B. L. P. Bloemers, A. M. van Furth, M. E. Weijerman et al., "Down syndrome: a novel risk factor for respiratory syncytial virus bronchiolitis-a prospective birth-cohort study," Pediatrics, vol. 120, no. 4, pp. e1076-e1081, 2007.

[48] K. Thorburn, M. Eisenhut, and A. Riordan, "Mortality and morbidity of nosocomial respiratory syncytial virus (RSV) infection in ventilated children-a ten year perspective," Minerva Anestesiologica, vol. 78, no. 7, p. 782, 2012.

[49] K. Thorburn, "Pre-existing disease is associated with a significantly higher risk of death in severe respiratory syncytial virus infection," Archives of Disease in Childhood, vol. 94, no. 2, pp. 99-103, 2009.

[50] R. Singleton, L. Dooley, D. Bruden, S. Raelson, and J. C. Butler, "Impact of palivizumab prophylaxis on respiratory syncytial virus hospitalizations in high risk Alaska Native infants," The Pediatric Infectious Disease Journal, vol. 22, no. 6, pp. 540-545, 2003.

[51] N. T. Petersen, N. Hoiby, and C. H. Mordhorst, "Respiratory infections in cystic fibrosis patients caused by virus, chlamydia and mycoplasma-possible synergism with Pseudomonas aeruginosa," Acta Paediatrica Scandinavica, vol. 70, no. 5, pp. 623-628, 1981.

[52] B. Paes and P. Manzoni, "Special populations: do we need evidence from randomized controlled trials to support the need for respiratory syncytial virus prophylaxis?" Early Human Development, vol. 87, supplement 1, pp. S55-S58, 2011.

[53] R. Giusti, "North american synagis prophylaxis survey," Pediatric Pulmonology, vol. 44, no. 1, pp. 96-98, 2009.

[54] D. Borowitz, K. A. Robinson, M. Rosenfeld et al., "Cystic fibrosis foundation evidence-based guidelines for management of infants with cystic fibrosis," The Journal of Pediatrics, vol. 155, supplement 6, pp. S73-S93, 2009.

[55] K. A. Robinson, I. J. Saldanha, and N. A. McKoy, "Management of infants with cystic fibrosis: a summary of the evidence for the cystic fibrosis foundation working group on care of infants with cystic fibrosis," The Journal of Pediatrics, vol. 155, supplement 6, pp. S94-S105, 2009. 
[56] C. Sommer, B. Resch, and E. A. Simões, "Risk factors for severe respiratory syncytial virus lower respiratory tract infection," The Open Microbiology Journal, vol. 5, pp. 144-154, 2011.

[57] G. F. Langley and L. J. Anderson, "Epidemiology and prevention of respiratory syncytial virus infections among infants and young children," The Pediatric Infectious Disease Journal, vol. 30, no. 6, pp. 510-517, 2011.

[58] A. Banerji, D. Greenberg, L. F. White et al., "Risk factors and viruses associated with hospitalization due to lower respiratory tract infections in canadian inuit children: a case-control study," The Pediatric Infectious Disease Journal, vol. 28, no. 8, pp. 697701, 2009.

[59] R. J. Singleton, D. Bruden, L. R. Bulkow, G. Varney, and J. C. Butler, "Decline in respiratory syncytial virus hospitalizations in a region with high hospitalization rates and prolonged season," The Pediatric Infectious Disease Journal, vol. 25, no. 12, pp. 1116$1122,2006$.

[60] A. Dede, D. Isaacs, P. J. Torzillo et al., "Respiratory syncytial virus infections in Central Australia," Journal of Paediatrics and Child Health, vol. 46, no. 1-2, pp. 35-39, 2010. 


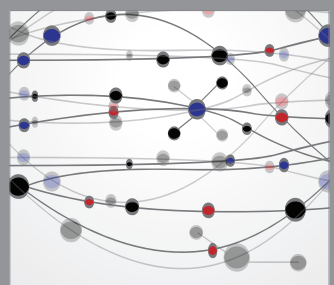

The Scientific World Journal
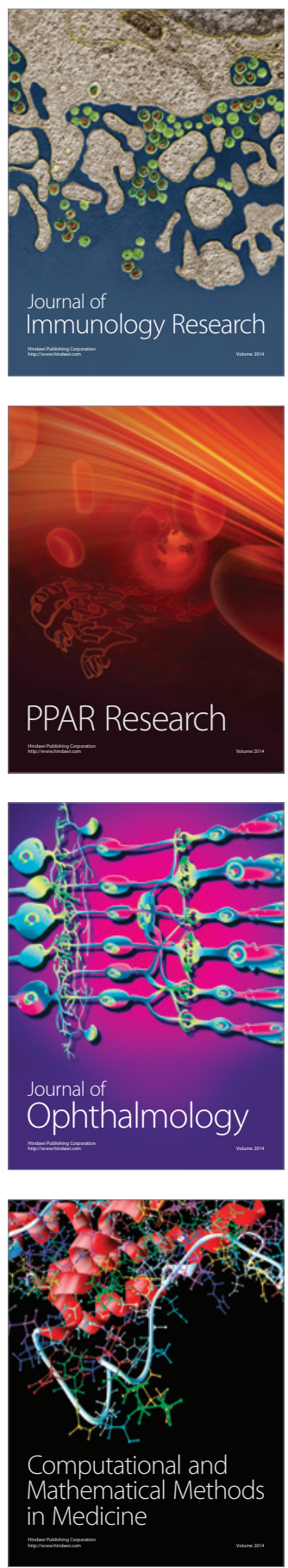

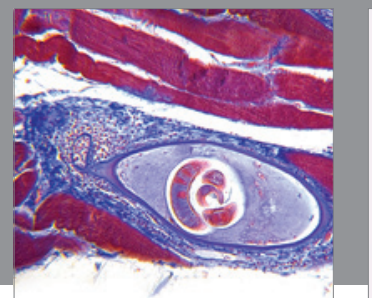

Gastroenterology

Research and Practice
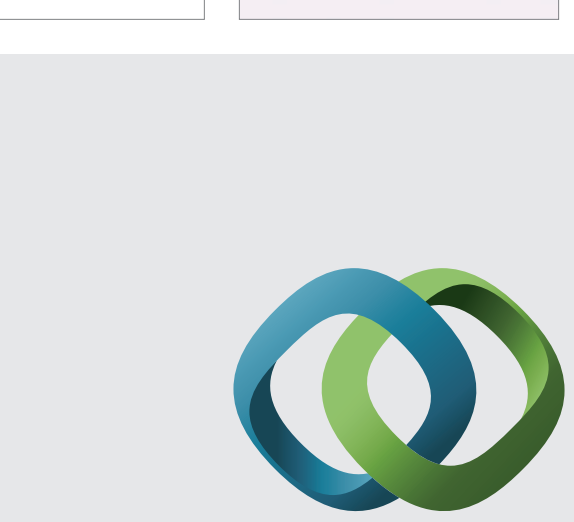

\section{Hindawi}

Submit your manuscripts at

http://www.hindawi.com
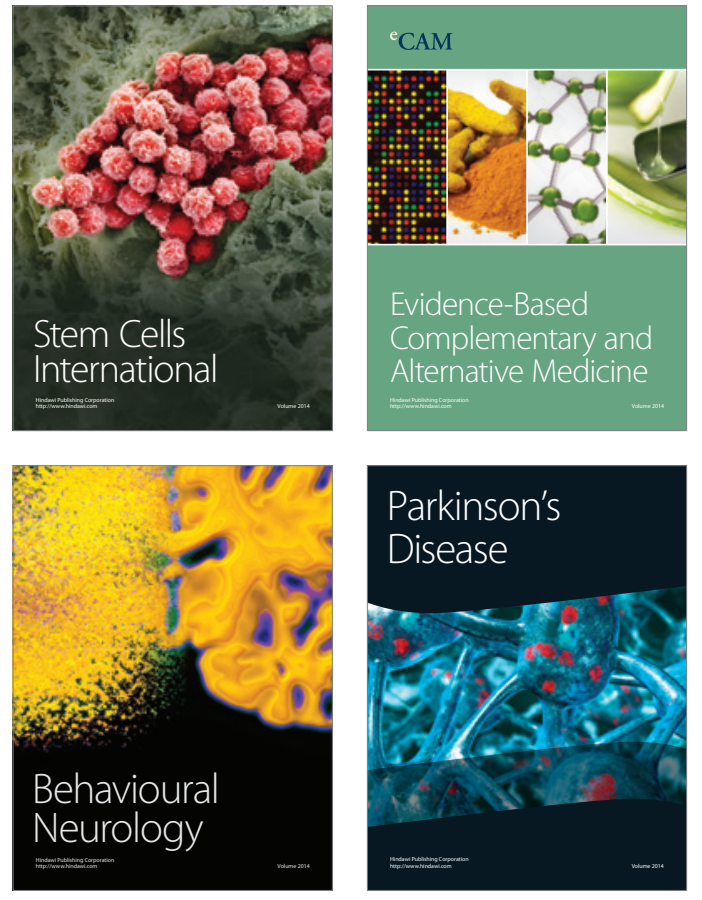
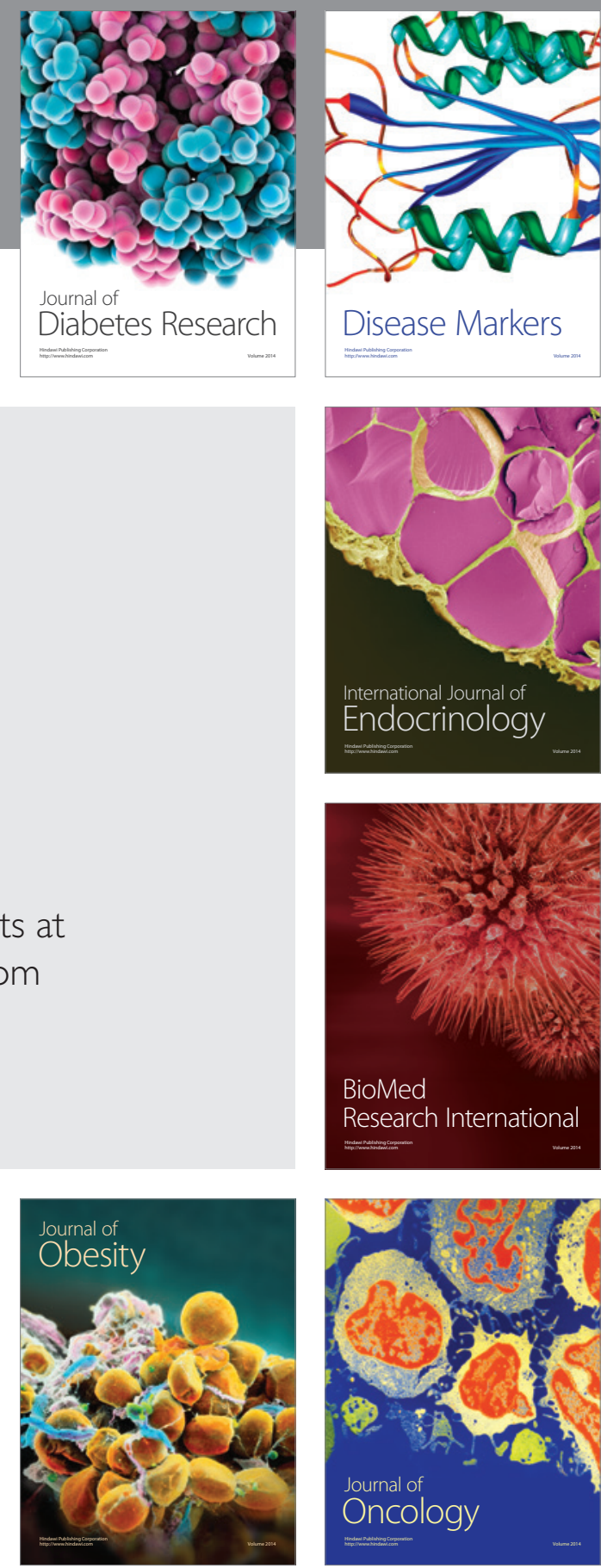

Disease Markers
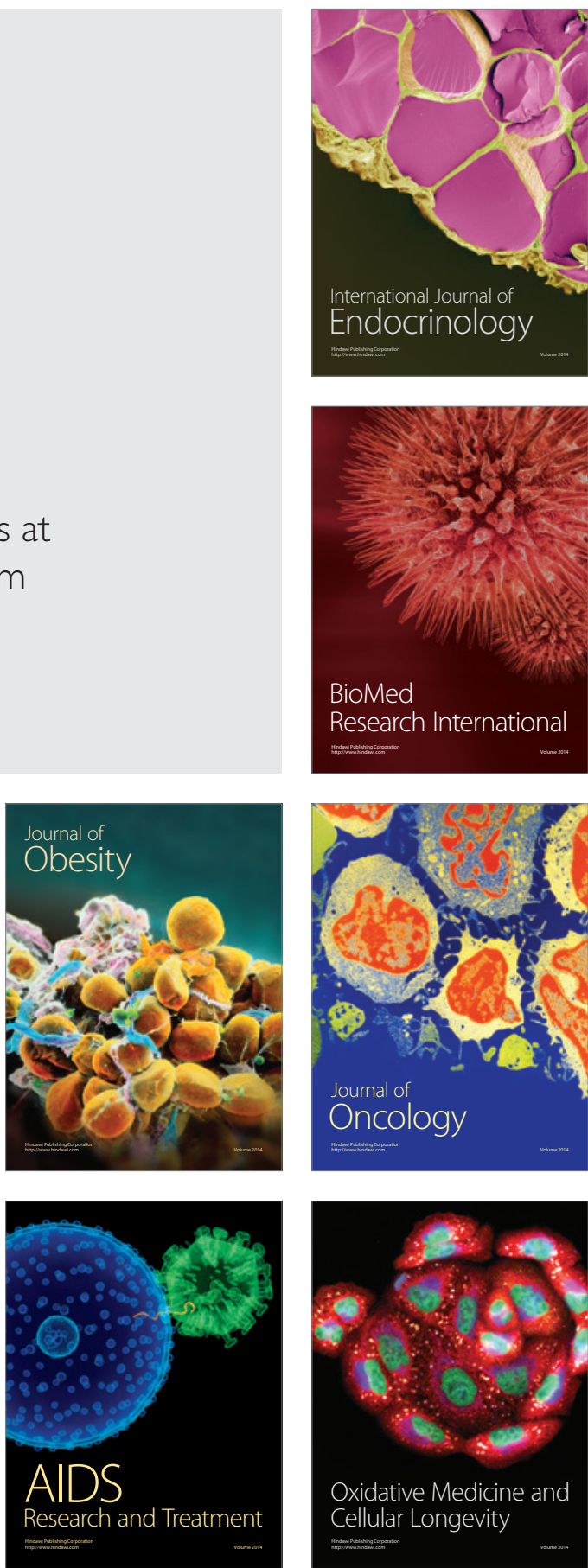